$0,96)$, giữa các độ tuổi $(p=0,29)$ về kiến thức chung, thái độ chung và thực hành chung về phòng, chống dịch COVID-19.

- Có sự khác biệt kiến thức chung, thái đô chung và thực hành chung về phòng, chống dịch COVID-19 với dân tộc $(p<0,01)$, tôn giáo $(p<0,01)$, trình độ học vấn $(p<0,01)$, nghề nghiệp $(p<0,01)$, kinh tế hộ gia đình $(p<0,01)$ và khu vực sinh sống $(p<0,01)$.

- Nguồn thông tin về dịch COVID-19 từ báo chí, truyền hình, internet, mạng xã hội, hàng xóm và người thân có liên quan đến kiến thức chung, thái độ chung và thực hành chung phòng, chống dịch COVID-19 $(p=0,000)$. Nguồn thông tin về dịch COVID-19 từ loa phát thanh chỉ có liên quan đến kiến thức chung $(p=0,001)$.

- Có mối tương quan thuận giữa kiến thức chung với thái độ chung $(r=0,490, N=1.154$ và $\mathrm{p}=0,000)$ và thực hành chung $(\mathrm{r}=0,601$, $\mathrm{N}=1.154, \mathrm{p}=0,000$ ) về phòng chống dịch COVID19. Có mối tương quan thuận giữa thái độ chung với thực hành chung $(r=0,545, n=1.154$, $\mathrm{p}=0,000$ ) về phòng chống dịch COVID- 19 .

\section{TÀI LIÊU THAM KHẢO}

1. Bộ Y tế. Quyết định số 3638/Q⿹-BYT ngày 30 tháng 07 năm 2021 của Bộ Y tế về việc ban hành "hướng dẫn tạm thời giám sát và phòng, chống COVID-19"

2. Sở Y tế Đắk Lắk. Báo cáo nhanh số 819/BC-SYT ngày 07/12/2021 của Sở Y tế Đắk Lắk về tình hình phòng, chống dịch COVID-19 trên địa bản tỉnh Đắk Lắk.

3. Yimer $M$, Abera B, Mulu W, Bezabih B. Knowledge, attitude and practices of high risk populations on louse-borne relapsing fever in Bahir Dar city, north-west Ethiopia. Sci J Public Health. 2014;2(1):15-22. doi:10.11648/j.sjph.20140201.13

4. Koo H-C, Poh B, Ruzita A. Assessment of knowledge, attitude and practice towards whole grains among children aged 10 and 11 years in Kuala Lumpur. Int J Food Sci Nutr Diet. 2015; 4(1):171-177.doi:10.19070/2326-3350-1500032

5. Seid MA, Hussen MS. Knowledge and attitude towards antimicrobial resistance among final year undergraduate paramedical students at University of Gondar, Ethiopia. BMC Infect Dis. 2018;18(1):312. doi:10.1186/s12879-018-3199-1

6. Hoang Bac Nguyen, Thi Hong Minh Nguyen, Thi Thanh Tam Tran, Thi Hong Nhan Vo, Van Hung Tran, Thi Nam Phuong Do, Quang Binh Truong, Thi Hiep Nguyen, and Loan Khanh Ly. Knowledge, Attitudes, Practices, and Related Factors Towards COVID-19 Prevention Among Patients at University Medical Center Ho Chi Minh City, Vietnam. https://www.ncbi.nlm.nih.gov/pmc/articles/PMC81 63721/\#cit0017. Truy cập ngày 22/11/2021.

7. Amirhossein Erfani, Reza Shahriarirad, Keivan Ranjbar, Alireza Mirahmadizadeh \& Mohsen Moghadami. Knowledge, Attitude and Practice toward the Novel Coronavirus (COVID-19) Outbreak: A Population-Based Survey in Iran. https://www.who.int/bulletin/online first/20256651.pdf. Truy cập ngày 23/11/20021.

8. Cổng thông tin điên tử tỉnh Đắk Lắk. https://daklak.gov.vn/tong-quan-dak-lak//asset_publisher/bDngMUmMrWIw/content/i-ieukien-tu-nhien. Trưy cập ngày 24/11/2021.

9. Bệnh viện Nguyễn T̛ri Phương. Khảo sát sư hiểu biết về COVID-19 của người dẫn đến khám chữa bệnh tại bệnh viện Nguyễn Tri Phương. https://bvnguyentriphuiong.com.vn/nghien-cuunoi-bo-va-dang-tai-tap-chi-trong-nuoc/khao-sat-suhieu-bietkhao-sat-su-hieu-biet-ve-covid-19-cuanguoi-dan-den-kham-chua-benh-tai-benh-viennguyen-tri-phuong-ve-covid-19-cua-nguoi-danden-kham-chua-benh-tai-benh-vien-nguyen-triphuong. Truy cập ngày 25/11/2021.

\title{
ĐĂC ĐIỂM LÂM SÀNG TIC ÂM THANH Ở HộI CHỨNG TOURETTE
}

\section{TÓM TẮT}

Nghiên cứu rối loạn Tic ở trẻ có hội chứng Tourette với mục tiêu mô tả đặc điểm lâm sàng Tic âm thanh ở trẻ được chẩn đoán mắc hội chứng Tourette bằng phương pháp mô tả cắt ngang ở 77 trẻ đến khám lần đâu tiên tại phòng khám chuyên khoa Tâm thần, Bệnh viện Nhi Trung ương, có tuổi dưới 18 , được chẩn đoán

\section{${ }^{1}$ Dai họ Y Hà Nôi}

2 Viện Sức Khỏe Tâm Thần - Bệnh Viện Bạch Mai

Chịu trách nhiệm chính: Dương Minh Tâm

Email: duongminhtam@hmu.edu.vn

Ngày nhận bài: 22.10.2021

Ngày phản biện khoa học: 20.12.2021

Ngày duyệt bài: 28.12.2021

\section{Trần Nguyễn Ngọc ${ }^{1,2}$, Dương Minh Tâm ${ }^{1,2}$}

xác định hội chứng Tourette (F95.2) theo tiêu chuẩn chẩn đoán của ICD 10. Kết quả: phân lớn các động tác tic âm thanh khởi phát khi trẻ dưới 7 tuổi: $62,3 \%$, chỉ có $1,3 \%$ trẻ khởi phát ở tuổi trên 11 . Phân lớn bệnh nhân nhâan được chẩn đoán hội chứng Tourette ở lứa tuổi $8-11$ (55,8\%). Các triêu chứng tic âm thanh đơn giản xuất hiện đa dang: hắng giọng là biểu hiện gặp nhiêu nhất, nhiều hơn rõ rệt so với các biểu hiện khác: $66,2 \%$ ); tiếp theo khit mũi: $18,2 \%$ và khac: $15,6 \%$. Chỉ có 3 triệu chứng Tic âm thanh phức tạp xuất hiện, đó là: nói tục: $2,6 \%$; nói lắp bắp:2,6\% và phát âm không rõ: $1,3 \%)$. Kết luận: Phát hiện sớm các triệu chứng tic âm thanh là điều quan trong trong chẩn đoán chính xác hội chứng Tourette, để từ đó bệnh nhân có thể được điều trị kịp thời.

Tư' khoá: hội chứng Tourette; Tic âm thanh; trẻ em. 


\section{SUMMARY \\ CLINICAL FEATURES OF VOCAL TICS OF TOURETTE SYNDROME}

Study aims to describe clinical features of vocal tics in children with Tourette syndrome. This is a cross-sectional study enrolled 77 children under 18 years olds, in the first diagnostic of Tourette syndrome (F95.2) at the outpatient clinic, Department of Psychiatry, National Children's Hospital. Results: In majority of cases, onset of vocal tics was before the age of $7,(62.3 \%)$. There is only $1,3 \%$ of patients have first symptoms after the age of 11 . Most children were given diagnosis of Tourette syndrome between 8 and 11 years old (55.8\%). There are 11 simple vocal tics were observed. The most common was throat clearing $(66.2 \%)$, followed by snorting $(18.2 \%)$ and spitting $15.6 \%$. In our study, only 3 complex vocal tics occured in children with Tourette syndrome, including profanity $(2.6 \%)$ and stuttering $(2.6 \%)$ and unclear pronunciation $(1.3 \%)$. Conclusion: Recognizing vocal tics are very important in early diagnosis of Tourette syndrome, which helps patients treated appropriately.

Keywords: Tourette's syndrome; Tic characteristics; children.

\section{I. ĐĂTT VẤN ĐỀ}

Hội chứng Tourette là một rối loạn tâm - thần kinh đặc trưng bởi nhiều tic vận động và ít nhất một tic âm thanh xuất hiện trên 1 năm, khởi phát trước 18 tuổi. Tic là dấu hiệu đặc trưng nhất của hội chứng Tourette trong đó Tic âm thanh được khái niệm là những âm thanh vô nghĩa phát ra môt cách đột ngột không mục đích. ${ }^{1}$ Hình thái của Tic âm thanh rất đa dạng, phức tạp và thường bị nhầm lẫn với các bệnh lý đường hô hấp như hen phế quản, viêm phế quản hoặc viêm mũi di ứng. Thông thường, Tic xuất hiện khoảng 15 - 25\% ở nhóm trẻ từ $4-7$ tuổi với các biểu hiện nhẹ và thoáng qua trong vòng vài tháng. Xu hướng tăng dần về mức độ, tần số, sẽ đạt đến đỉnh điểm ở độ tuổi từ 10 - 12 và sau đó sẽ giảm dần khi trẻ bước sang tuổi vị thành niên. Khoảng $2 / 3$ cho đến $3 / 4$ trẻ có các dấu hiệu tic giảm một cách đáng kể trong suốt thời kỳ vị thành niên. Một số ít các trường hợp có thể kéo dài đến tuổi trưởng thành và khi đó khả năng sẽ tồn tại trong suốt cuộc đời. ${ }^{1,2}$ Cho đến nay, chẩn đoán hội chứng Tourette chủ yếu dựa vào lâm sàng. Chưa có xét nghiệm cận lâm sàng hỗ trợ chẩn đoán hội chứng Tourette. Các xét nghiệm cận lâm sàng chỉ giúp chẩn đoán loại trừ với các triệu chứng, hội chứng hoăc bênh lý khác.

Taii Việt Nam, đã có một số đề tài nghiên cứu về các rối loạn tic nhưng chưa có đề tài nghiên cứu về đặc điểm tic âm thanh ở hội chứng Tourette. Vì vậy với mong muốn làm rõ đặc điểm lâm sàng, chúng tôi thực hiện nghiên cứu với mục tiêu "Mô tả đặc điểm lâm sàng tic âm thanh ở trẻ được chẩn đoán mắc hội chứng Tourette".

II. ĐốI TƯợNG VÀ PHƯƠNG PHÁP NGHIÊN CỨU

2.1. Thiết kế nghiên cứu: mô tả cắt ngang. 2.2. Thời gian, đối tượng và địa điểm nghiên cứu

2.2.1. Thời gian nghiên cứu: Tháng 8 năm 2020 đến tháng 8 năm 2021.

2.2.2. Đối tượng nghiên cứu. Nghiên cứu lựa chọn đối tượng tham gia là (i) trẻ em đến khám lần đầu tiển tại phòng khám chuyên khoa Tâm thần - Bệnh viện Nhi Trung ương; (ii) có độ tuổi dưới 18; (iii) được chẩn đoán hội chứng Tourette (F95.2) theo tiêu chuẩn chẩn đoán của ICD 10; (iv) có thông tin đầy đủ về hành chính, tiền sứ, bênh sử, khám lâm sàng, các thông số cận lâm sàng; (v) sử dụng thuốc điều trị tic; và (vi) gia đình và bản thẩn trẻ đồng ý tự nguyện tham gia nghiên cứu. Nghiên cứu loại những trẻ (i) có bệnh lý thực thể ảnh hưởng đển hoạt động chức nẳng não, tổn thương thực thể nã̉o kèm theo; (ii) nghiện chất hoặc lạm dụng chất; (iii) bố/mẹ/người chăm sóc trẻ không có khả năng hiểu, trả lời trong quá trình thu thập thông tin và thực hiện thang đo tâm lý, không tuân thủ quá trình nghiên cứu; (iv) bố/mẹ/người chăm sóc trẻ mắc bệnh lý tâm thần và đang điều trị trong quá trình thực hiện nghiên cứu.

2.2.3. Địa điểm nghiên cứu. Nghiên cứu được tiến hành tại phòng khám chuyên khoa Tâm thần - Bệnh viên Nhi Trung ương.

2.3. Cỡ mẫu và cách chọn mẫu. Nghiên cứu sử dụng cách chọn mẫu thuận tiện, lựa chọn tuần tự các bệnh nhân đáp ứng những tiều chuẩn lựa chọn ở trên trong thời gian từ tháng 8 năm 2020 đển tháng 8 năm 2021. Tổng cộng cỡ mẫu thu được là 77 trẻ.

2.4. Biển số nghiên cứu. Giới tính, tuổi khởi phát, tuổi chẩn đoán bệnh, thời gian trễ của chẩn đoán, hình thái Tic âm thanh đơn và hình thái Tic âm thanh phức tạp.

2.5. Công cụ thu thập số liệu. Bệnh án nghiên cứu (được thiết kế riêng phù hợp với nghiên cứu)

2.6. Phân tích số liệu. Nhập liệu và xử lý số liệu bằng phần mềm thống kê SPSS 20.0

2.7. Đạo đức nghiên cứu. Hội đồng đạo đức của Bệnh viện Nhi Trung ương thông qua số 1661/BVNTW-VNCSKTE

\section{KẾT QUẢ NGHIÊN CỨU \\ Bảng 3.1. Đặc điểm tuổi của đôî tượng nghiên cứu $(n=77)$}


VIETNAM MEDICAL JOURNAL N¹ - JANUARY - 2022

\begin{tabular}{|c|c|c|c|c|}
\hline \multirow{2}{*}{ Nhóm tuổi } & \multicolumn{2}{|c|}{$\begin{array}{c}\text { Tuổi khởi } \\
\text { phát }\end{array}$} & \multicolumn{2}{c|}{$\begin{array}{c}\text { Tuối chẩn } \\
\text { đoán }\end{array}$} \\
\cline { 2 - 5 } & SL & $\mathbf{\%}$ & SL & \% \\
\hline$\leq 7$ tuối & $\mathbf{4 8}$ & $\mathbf{6 2 , 3}$ & 20 & 26,0 \\
\hline $8-11$ tuối & 28 & 36,4 & $\mathbf{4 3}$ & $\mathbf{5 5 , 8}$ \\
\hline$>11$ tuối & 1 & 1,3 & 14 & 18,2 \\
\hline Tổng & 77 & 100 & $\mathbf{7 7}$ & $\mathbf{1 0 0 \%}$ \\
\hline$p$ & \multicolumn{2}{|c|}{$<0,01$} & \multicolumn{2}{|c|}{$<\mathbf{0 , 0 1}$} \\
\hline
\end{tabular}

Nhân xét. Phần lớn Tic khởi phát ở đô tuổi $\leq$ 7 với tî lệ $62,3 \%$, ít gặp nhất là Tic khởi phát ở độ tuổi > 11(1,3\%). Đa số Tic được chẩn đoán ở độ tuổi $8-11$ tuổi với tỉ lệ 55,8 \%.

Bảng 3.2. Trung binh tuổi và thời gian trễ của chẩn đoán ( $n=77)$

\begin{tabular}{|c|c|c|c|c|}
\hline $\begin{array}{c}\text { Biến số } \\
\text { (đơn vị năm) }\end{array}$ & $\begin{array}{c}\text { Trung } \\
\text { bình }\end{array}$ & Min & Max & $\mathbf{p}$ \\
\hline Tuổi khởi phát & $\begin{array}{c}6,75 \pm \\
2,42\end{array}$ & 2 & 12 & \multirow{2}{*}{$\begin{array}{c}< \\
0,01^{*}\end{array}$} \\
\hline Tuổi chẩn đoán & $\begin{array}{c}9,08 \pm \\
2,21\end{array}$ & 4 & 13 & \\
\hline $\begin{array}{l}\text { Thời gian trề } \\
\text { của chẩn đoán }\end{array}$ & $\begin{array}{c}2,32 \pm \\
1,8\end{array}$ & 1 & 8 & \\
\hline
\end{tabular}

Nhân xét. Tuối trung bình được chân đoán $(9,08 \pm 2,21)$ cao hơn tuổi trung bình khởi phát $6,75 \pm 2,42(p<0,01)$. Trung bình thời gian trễ của chẩn đoán là $2,32 \pm 1,8$.

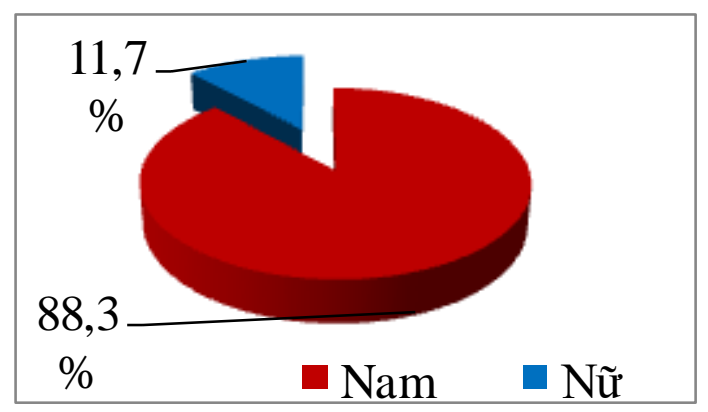

Biêu đồ 3.1. Phân bố giới tính $(n=77)$

Nhận xét. Trẻ nam chiếm đa số $(88,3 \%)$, tỷ lệ nam/nữ = 7,5/1 (p < 0,01)

Bảng 3.3. Hình thái Tic âm thanh đơn giản $(n=77)$

\begin{tabular}{|c|c|c|c|c|}
\hline \multirow{2}{*}{$\begin{array}{c}\text { Hình thái Tic âm } \\
\text { thanh đơn giản }\end{array}$} & \multicolumn{2}{|c|}{$\begin{array}{c}\text { Lúc khởi } \\
\text { phát }\end{array}$} & \multicolumn{2}{c|}{$\begin{array}{c}\text { Lúc chấn } \\
\text { đoán }\end{array}$} \\
\cline { 2 - 5 } & $\mathbf{S L}$ & $\mathbf{\%}$ & $\mathbf{S L}$ & $\mathbf{\%}$ \\
\hline Khịt mũi & 14 & 18,2 & 23 & 29,9 \\
\hline Tiếng mút môi & 0 & 0,0 & 0 & 0,0 \\
\hline Hít vào & 0 & 0,0 & 1 & 1,3 \\
\hline $\begin{array}{c}\text { Thở ra tạo tiếng } \\
\text { động }\end{array}$ & 0 & 0,0 & 1 & 1,3 \\
\hline Thở rên (kêu gữ gừ) & 0 & 0,0 & 0 & 0,0 \\
\hline Tiếng rít & 0 & 0,0 & 0 & 0,0 \\
\hline Thối hoặc huýt gión & 0 & 0,0 & 0 & 0,0 \\
\hline Nấc & 2 & 2,6 & 3 & 3,9 \\
\hline Khạc & 3 & 3,9 & 12 & 15,6 \\
\hline
\end{tabular}

\begin{tabular}{|c|c|c|c|c|}
\hline Hắng giọng & 16 & 20,8 & 51 & $\mathbf{6 6 , 2}$ \\
\hline Ho & 0 & 0,0 & 2 & 2,6 \\
\hline Hắt hơi & 0 & 0,0 & 0 & 0,0 \\
\hline $\begin{array}{c}\text { Tiếng ợ hoặc nuốt } \\
\text { ực }\end{array}$ & 0 & 0,0 & 6 & 7,8 \\
\hline Tiếng sủa & 0 & 0,0 & 1 & 1,3 \\
\hline Tiếng lách cách & 0 & 0,0 & 0 & 0,0 \\
\hline Tiếng lục cục & 0 & 0,0 & 1 & 1,3 \\
\hline Tiếng xuỵt & 0 & 0,0 & 0 & 0,0 \\
\hline Tiếng kêu hoặc thét & 1 & 1,3 & 3 & 3,9 \\
\hline
\end{tabular}

Nhân xét. Tại thời điếm chân đoán, có 11 biểu hiện Tic âm thanh đơn giản trong tổng số 18 biểu hiện. Tỉ lệ cao là hắng giọng $(66,2 \%)$, tiếp đó khit mũi $(18,2 \%)$ và khac $15,6 \%$.

Bảng 3.4. Hinh thái Tíc âm thanh phức $\operatorname{tap}(n=77)$

\begin{tabular}{|c|c|c|c|c|}
\hline \multirow{2}{*}{$\begin{array}{c}\text { Hình thái Tic âm } \\
\text { thanh phức tạp }\end{array}$} & \multicolumn{2}{|c|}{$\begin{array}{c}\text { Lúc khởi } \\
\text { phát }\end{array}$} & \multicolumn{2}{c|}{$\begin{array}{c}\text { Lúc chấn } \\
\text { đoán }\end{array}$} \\
\cline { 2 - 5 } & $\mathbf{S L}$ & $\mathbf{\%}$ & $\mathbf{S L}$ & $\mathbf{\%}$ \\
\hline Nói từ vô nghĩa & 0 & 0,0 & 0 & 0,0 \\
\hline Nói lắp bắp & 0 & 0,0 & 2 & $\mathbf{2 , 6}$ \\
\hline Phát âm không rõ & 0 & 0,0 & 1 & 1,3 \\
\hline Nói kiếu định hình & 0 & 0,0 & 0 & 0,0 \\
\hline Lời lăng mạ & 0 & 0,0 & 0 & 0,0 \\
\hline Nói tục & 1 & 1,3 & 2 & $\mathbf{2 , 6}$ \\
\hline Nhại lời & 0 & 0,0 & 0 & 0,0 \\
\hline Câu nói rời rạc & 0 & 0,0 & 0 & 0,0 \\
\hline $\begin{array}{c}\text { Câu nói thay đối về } \\
\text { âm lượng }\end{array}$ & 0 & 0,0 & 0 & 0,0 \\
\hline
\end{tabular}

Nhân xét. Tai thời điếm chân đoán, có 3 biểu hiện trong số 9 biểu hiện Tic âm thanh. Hai biểu hiện có tî lệ như nhau là nói tục $(2,6 \%)$ và nói lắp bắp. Biểu hiện còn lại là phát âm không rõ với tỉ lệ 1,3\%.

\section{BÀN LUẬN}

Nghiên cứu cho thây hội chứng Tourette xuất hiện rất sớm từ những năm đâu của cuộc đời. Dữ liệu ghi nhận có 3 trẻ xuất hiện tic lẩn đâu tiên lúc 2 tuổi và 1 trẻ được chẩn đoán tại thời điểm nghiên cứu là 4 tuổi. Khoảng tuổi khởi phát dao động từ 2 - 12 tuổi. Trong đó, phân lớn là những trẻ ở nhóm từ 7 tuổi trở xuống (bảng 3.1). Tuổi khởi phát trung bình là $6,75 \pm 2,42$ (bảng 3.2). Tương tự như vậy, Hiệp hội Tourette quốc tế báo cáo tuổi khởi phát của trẻ mắc hội chứng Tourette dao động trong khoảng từ 2 - 20 với tuổi khởi phát trung bình là 6,4. Tỉ lệ nhóm tuổi khởi phát dưới 6 tuổi chiếm 41,1\%. Mặc dù tuổi khởi phát biểu hiện tic sớm nhưng tuổi được chẩn đoán hội chứng Tourette lại muộn. Nhóm tuổi được chẩn đoán chủ yếu từ 8 - 11 tuổi. Biên độ dao động từ 4 - 13 tuổi với 2 trẻ ở lứa tuổi 13. Tuổi trung bình là 9,08 $\pm 2,21$ (bảng 3.2). Kết quả trong nghiên cứu của chúng tôi tương 
đồng với kết quả của một số nghiên cứu khác. Nghiên cứu của Freeman và cộng sự trên một quần thể lớn với 3500 trường hợp mắc hội chứng Tourette cho kết quả đa số trẻ được chẩn đoán ở nhóm tuổi từ 6 - 10 với tỉ lệ 51,4\%. Tuổi trung bình được chẩn đoán là $13 .^{3}$ Schlander khảo sát với mẫu 2 triệu người ở Nordbaden, Tây Nam nước Đức cho biết tỉ lệ mắc hội chứng Tourette cao nhất là nhóm tuổi $7-12(0,040 \%)$, tiếp đó đến nhóm tuổi 13 - 18 với $(0,038 \%){ }^{4}$ Bên cạnh đó, chúng tôi phát hiện thây có một độ trễ trong chẩn đoán hội chứng Tourette. Một số tác giả cho biết phải mất $5-10$ năm từ khi tic bắt đầu xuất hiện đến khi được chẩn đoán. Trung bình 5,3 năm trong nghiên cứu của Debes và 6,4 năm trong nghiên cứu của Freeman. ${ }^{3}$ Độ trế trong chẩn đoán hội chứng Tourette có thể hiểu được là do tính chất xuất hiện và hình thái lâm sàng của tic luôn phong phú, phức tạp và biến thiên liên tục. Để chẩn đoán cần phải có nhiều tic vận động và ít nhất một tic âm thanh, có thể xuất hiện đồng thời hoặc không đồng thời và thời gian phải kéo dài ít nhất một năm. Một số trường hợp xuất hiện nhiều hình thái tic vận động trong thời gian một vài năm. Trong những trường hợp đó các bác sĩ sẽ chẩn đoán rối loạn tic vận động mạn tính. Chỉ khi có sự xuất hiện của tic âm thanh thì chẩn đoán là hội chứng Tourette mới được xác lập.

Theo y văn, hội chứng Tourette dao động từ 3 đến 8 trên 1.000 ở trẻ em trong độ tuổi đi học. Xu hướng xuất hiện ở trẻ trai nhiều hơn trẻ gái với tỷ lệ thay đổi từ 2:1 đến 4:1 (DSM5). Tî lệ nam giới so với nữ giới còn dao động nhiêuu hơn trong nghiên cứu của Freeman, từ $3: 1$ đến 10:17. Tương tự như vậy, Yang và cộng sự khảo sát trên 122.884 người Canada trong năm 2010 - 2011 cho biết ở độ tuổi 12 - 17 tỉ lệ mắc hội chứng Tourette ở nam giới là 6,03 trên 1000 ( $95 \% \mathrm{CI}: 3,24-8,81)$ và ở nữ giới là 0,48 trên 1.000 (95\%CI: 0,05 - 0,91). ${ }^{5}$ Hoặc nghiên cứu của ở vùng Nordbaden, Tây Nam nước Đức ghi nhận tỉ lệ nam giới là $0,015 \%$ và nữ giới là $0,005 \%{ }^{4}$ Chúng tôi cũng ghi nhận có tới 68 trẻ mắc hội chứng Tourette trong số 77 trẻ tham gia vào nghiên cứu. Tỉ lêt trẻ nam là $88,3 \%$ và trẻ nữ là $7,5: 1$. Giả thuyết được đưa ra là do sự hiện diện của các steroid androgen trong các giai đoạn quan trọng của sự phát triển của bào thai. Steroid androgen là các steroid đồng hóa bao gồm androgen tự nhiên như testosterone và androgen tổng hợp có liên quan về cấu trúc và có tác dụng tương tự như testosterone. Testosterone đóng một vai trò quan trọng trong sự phát triển của các mô sinh sản của nam như tinh hoàn, tuyến tiền liệt và đồng thời thúc đẩy các đặc tính sinh dục phụ như làm tăng cơ bắp, xương và sự phát triển tóc. Steroid androgen có thể ảnh hưởng đến sự phát triển của mạch thần kinh vỏ não - hạch nền và đặc biệt là hệ thống dopaminergic. Một số tác giả đã nhận định giới tính nam là yếu tố nguy cơ lớn nhất đối với hội chứng Tourette.

Tic được khái niệm là những cử động xuất hiện đột ngột, định hình, lặp đi lặp lại của một cơ hoặc một số nhóm cơ trển cơ thể hoặc những âm thanh vô nghĩa xuất hiện đột ngột không có mục đích. Trong thực hành lâm sàng mọi chuyển động đơn lẻ cũng có thể là một tic. Các động tác như run giật cớ, múa giật và loạn trương lực cơ đa phần bị nhầm với biểu hiện tic. Tuy nhiên, sự khác biệt của tic là những động tác nhanh, tái diễn, không nhịp điệu và định hình, đặc trưng về cường độ, tần số và sự lặp lại. Các tic được trẻ cảm nhận như không thể cưỡng lại được nhưng có thể dừng chúng lại trong những khoảng thời gian ngắn.

Với mục tiêu mô tả đặc điểm lâm sàng tic nhằm cung cấp một bức tranh lâm sàng chi tiết cho các bác sĩ Nhi khoa trong tiếp cận phát hiện và chẩn đoán rối loạn tic, chúng tôi đã quan sát và ghi chép thống kê mô tả các biểu hiện tic ở 77 trẻ được chẩn đoán xác định mắc hội chứng Tourette. Những biểu hiện tic đầu tiển cũng được khai thác và ghi chép tỉ mỉ. Theo quan sát của chúng tôi, biểu hiện Tic âm thanh không đa dạng như Tic vận động. Tại thời điểm khởi phát chỉ có 5 biểu hiện Tic âm thanh đơn giản ít hơn so với 16 biểu hiện Tic vận động đơn giản. Tại thời điểm chẩn đoán có 11 biểu hiên Tic vận động đơn giản trong khi đó có 18 biểu hiện Tic âm thanh đơn giản (bảng 3.3). Theo Leckman và cộng sự, Tic âm thanh thường khởi phát sau Tic vận động một đến hai năm với các biểu hiên đầu tiên là hắng giọng, khịt mũi và nói câu rời rạc. Tương tự như vậy, nghiên cứu của chúng tôi nhận thấy trong 5 biểu hiện Tic âm thanh thì tỉ lệ cao nhất là hắng giọng $(20,8 \%)$, tiếp đó đến khịt mũi là $18,2 \%$. Tic ầm thanh đơn giản có sự tiến triển theo thời gian về số lượng. Từ 5 biểu hiện Tic tại thời điểm khởi phát đã tăng lên 11 biểu hiện tại thời điểm chẩn đoán. Trong số 11 biểu hiện thì tỉ lệ cao nhất là hắng giọng $(66,2 \%)$, tiểp đó đến khịt mũi $(29,9 \%)$, và khạc $(15,6 \%)$. Một số biểu hiện Tic tại thời điểm khởi phát không xuất hiện nhưng đến thời điểm chẩn đoán đã xuất hiện là hít vào, thở ra tạo tiếng động, ho, tiếng ợ, nuốt ực, tiếng sủa, tiểng lục cục. Tại 
thời điểm chẩn đoán nghiên cứu ghi nhân có 11 biểu hiện Tic trong tổng số 18 biểu hiện âm thanh đợn giản. Tỉ lệ gặp nhiều nhất là biểu hiện hắng giọng $(66,2 \%)$, tiếp đó đến khịt mũi $(29,9 \%)$ và khạc $(15,6 \%)$ (bảng 3.3$)$. Tic âm thanh đơn giản được tạo ra bởi một luồng không khí qua dây thanh âm, miệng hoặc mũi. Chính vì vậy mà những biểu hiện như hắng giọng, khịt mũi hoặc khạc phần lớn bị nhầm với những bệnh đường thở như hen phế quản, viêm họng hoặc viêm mũi dị ứng. ${ }^{6}$

Biểu hiện lâm sàng của Tic âm thanh phức tạp không nhiều và sự xuất hiện của Tic không thường xuyên. Tỉ lệ chỉ từ $1,3-2,6 \%$. Tại thời điểm khởi phát, chỉ có 1 biểu hiện Tic âm thanh phức tap trong tổng số 9 biểu hiên được khảo sát. Biểu hiên đó là nói tục với tỉ lệ $1,3 \%$. Tại thời điểm chẩn đoán, có 3 biểu hiện trong số 9 biểu hiện Tic âm thanh. Hai biểu hiện có tỉ lệ như nhau là nói tục $(2,6 \%)$ và nói lắp bắp. Biểu hiên còn lại là phát âm không rõ với tỉ lệ $1,3 \%$ (bảng 3.4). Tương đồng với nhận định của chúng tôi, Hashemiyoon và cộng sự cho biết Tic âm thanh phức tạp thường gặp là phát âm không rõ, nói lắp bắp và nói tục. ${ }^{7}$ Nói tục là hiện tượng thốt ra những từ ngắn được được coi là ngôn ngữ xấu thường là tục tĩu. Nói tục là một biểu hiện của hội chứng Tourette nhưng nó không đặc hiêuu và không xuất hiện nhiều. Nghiên cứu theo dõi dọc trên 61 trẻ mắc hội chứng Tourette trong thời gian $4-8$ năm cho biết tỉ lê nói tục chiếm $9,8 \%{ }^{7}$ Khác với nhân định của Hashemiyoon, Andrea G Ludolph cho biết nói tục là biểu hiện lâm sàng thường xuất hiện ở hội chứng Tourette. Tỉ lệ xuất hiện từ 19 - 32\% trẻ mắc hội chứng Tourette. Một số nghiên cứu còn phát hiên thêm những biểu hiên khác của Tic âm thanh phức tạp. Nghiên cứu của Min và Lee ở Hàn Quốc phát hiện $13 \%$ trường hợp nhại lời. Nghiên cứu của Reguer và cộng sự ở Đan Mạch phát hiện 34\%. Nghiên cứu của Shapiro ở Mỹ phát hiện $18 \%$. Hoặc nghiên cứu của Lees và cộng sự ở Anh phát hiện $17 \%$ trường hợp nói lắp bắp. Nghiên cứu của Chee ở Úc phát hiên $8 \%$ trường hợp nói lắp bắp trong tổng số 50 trường hợp. Điều này cho thấy số lượng và tỉ lệ xuất hiện các Tic âm thanh phức tạp khác nhau ở mỗi nghiên cứu. Không có quy luật rõ ràng cho sự xuất hiên của các Tic âm thanh phức tạp. ${ }^{8}$ Thông thường thời gian khởi phát của những biểu hiện này sau khi xuất hiện các Tic khác khoảng $4-5$ năm và đa phần khởi phát ở tuổi 15. Chúng tôi tiến hành nghiên cứu cắt ngang những trẻ đến khám tại khoa Tâm thần bệnh viện Nhi trung ương tại 1 thời điểm nhất định. Do đó mà Tic âm thanh đơn giản và Tic âm thanh phức tạp cũng như tỉ lệ của các Tic âm thanh khác so với hơn các nghiến cứu. Nhìn chung biểu Tic âm thanh phong phú và dao động như Tic vận động. Điều này đòi hỏi bác sĩ cần phải khám xét kỹ càng và tỉ mỉ để tránh bỏ sót.

\section{KẾT LUÂN}

Tại thời điểm chẩn đoán có $11 / 18$ biểu hiện tic âm thanh đơn giản xuất hiện ở trẻ. Gặp nhiều nhất là hắng giọng $(66,2 \%)$, tiếp đó khịt mũi $(18,2 \%)$ và khạc $15,6 \%$. Chỉ có $3 / 9$ biểu hiện Tic âm thanh phức tạp xuất hiện ở trẻ đó là nói tục $(2,6 \%)$ và nói lắp bắp $(2,6 \%)$ và phát âm không rõ $(1,3 \%)$.

Khuyến nghị. Tic âm thanh thường gặp ở lứa tuổi học sinh và dễ nhầm lẫn với các bệnh lý đường hô hấp như hen phế quản, viêm phế quản và viêm mũi dị ứng. Do đó, bác sĩ Nhi khoa và bác sĩ Tâm thần cần hiểu rõ đặc điểm lâm sàng Tic âm thanh để chẩn đoán đúng. Qua đó sẽ điều trị hiệu quả.

Lời cảm ơn. Tôi xin chân thành cám ơn các trẻ và gia đình trẻ trong nghiên cứu, khoa Tâm thần, Bệnh viện Nhi Trung ương và Bộ môn Tâm thần, Trường Đại học Y Hà Nội đã tạo điều kiện cho việc thực hiện nghiên cứu.

\section{TÀI LIÊU THAM KHẢO}

1. Cohen S, Leckman JF, Bloch MH. Clinical Assessment of Tourette Syndrome and Tic Disorders. Neurosci Biobehav Rev. 2013;37(6):997-1007.

doi:10.1016/j.neubiorev.2012.11.013

2. Leckman JF, King RA, Bloch MH. Clinical Features of Tourette Syndrome and Tic Disorders. J Obsessive-Compuls Relat Disord. 2014;3(4):372379. doi:10.1016/j.jocrd.2014.03.004

3. Freeman RD, Fast DK, Burd L, Kerbeshian J, Robertson MM, Sandor P. An international perspective on Tourette syndrome: selected findings from 3,500 individuals in 22 countries. Dev Med Child Neurol. 2000;42(7):436-447. doi:10.1017/s0012162200000839

4. Schlander $M$, Schwarz $O$, Rothenberger $A$, Roessner V. Tic disorders: administrative prevalence and co-occurrence with attentiondeficit/hyperactivity disorder in a German community sample. Eur Psychiatry J Assoc Eur Psychiatr. doi:10.1016/j.eurpsy.2009.10.003

5. Yang J, Hirsch L, Martino D, Jette N, Roberts J, Pringsheim $\mathbf{T}$. The prevalence of diagnosed tourette syndrome in Canada: A national population-based study. Mov Disord Off J Mov Disord Soc. 2016;31(11):1658-1663. doi:10.1002/mds.26766

6. Ludolph AG, Roessner V, Münchau A, MüllerVahl K. Tourette Syndrome and Other Tic 
Disorders in Childhood, Adolescence and Adulthood. Dtsch Ärztebl Int. 2012;109(48):821288. doi:10.3238/arztebl.2012.0821

7. Hashemiyoon R, Kuhn J, Visser-Vandewalle V. Putting the Pieces Together in Gilles de la Tourette Syndrome: Exploring the Link Between Clinical Observations and the Biological Basis of
Dysfunction. Brain Topogr. 2017;30(1):3-29. doi:10.1007/s10548-016-0525-z

8. Chee KY, Sachdev $\mathbf{P}$. The clinical features of Tourette's disorder: an Australian study using a structured interview schedule. Aust $\mathrm{N} Z$ J Psychiatry. $1994 ; 28(2): 313-318$. doi:10.1080/00048679409075645

\title{
KẾT QUẢ LÂM SÀNG CỦA CÁC TRƯỜNG HỢP CHUYỂN Mô̂T PHÔI NANG QUA PHƯƠ'NG PHÁP NUÔI CẤY TIME LAPSE TẠI TRUNG TÂM HỖ TRỢ SINH SẢN VINMEC TIMES CITY
}

\author{
Diêm Thị Yến*, Lê Thị Phương Lan*, Nguyễn Thị Cẩm Vân* \\ Nguyễn Thị Như Trang*, Trần Huệ Trân*, Trương Văn Hạnh*, \\ Khuất Hữu Quân*, Nguyễn Vũ Hà*, Vũ Văn Thành*, Vũ Thị Liên*
}

\section{TÓM TẮT}

Mục tiêu: Phân tích mối liên quan giữa các bất thường xuất hiện trong quá trình phân chia của phôi giai đoạn sớm và kết quả lâm sàng. Đối tượng và phương pháp nghiên cứu: Nghiên cứu tiến hành trên 88 trường hợp chuyển 1 phôi nang trong chu kỳ chuyển phôi đông lanh, các phôi được tao ra từ chu kỳ thụ tinh ống nghiệm và nuôi cấy phôi bằng hệ thống timelapse. Các bệnh nhân sẽ được đánh giá kết quả có thai bằng xét nghiệm ßhcg vào ngày 14 sau chuyển phôi và siêu âm theo dõi đến thai diễn tiến, sau 10 tuần. Kết quả: tỷ lệ $\beta$ hcg $(+)$, thai lâm sàng, thai diễn tiến lần lướt là $62,5 \%, 55,7 \%, 51,1 \%$. Trong đó, tỷ lệ có thai của nhóm không xuất hiện bất thường trong phân chia giai đoạn đâu cao hơn so với nhóm bất thường ở cả 2 lần phân chia đâuu tiên, về tỷ lệ ßhcg $(+)(67 \%$ so với $51 \%)$, tỷ lê thai lâm sàng $(61 \%$ so với $41 \%$ ) và tỷ lệ thai diển tiến (56\% so với $37 \%$ ), tuy nhiên sự khác biệt không có ý nghĩa thống kê. Không ghi nhận trường hợp có thai nào khi chuyển các phôi có hình thành khổng bào trong phôi bào giai đoạn phôi dâu. Kết luận: những phôi không xuất hiện bất thường trong những lần phân chia đầu tiên của phôi sẽ mang lại kết quả có thai tốt hơn so với những phôi có bất thường xuất hiện 2 lần. Tuy nhiên, cần thực hiện nghiên cứu với cõ mẫu lớn hơn để thu được kết quả có độ tin cậy cao hơn.

\section{SUMMARY}

THE CLINICAL OUTCOME OF ONE BLASTOCYST TRANSFER THROUGH TIMELAPSE TECHNIQUE AT ART CENTER, VINMECTIMES CITY HOSPITAL

Objective: Analysis of the association between abnormal morphokinetics of early embryos and clinical outcomes. Materials and Methods: the study

*Tt hỗ trợ sinh sản, Bệnh viện Vinmec Times City Chịu trách nhiệm chính:

Email: drdiemyen@gmail.com

Ngày nhân bài: 25.10.2021

Ngày phản biện khoa học: 21.12.2021

Ngày duyệt bài: 28.12.2021 conducted on 88 frozen embryo transfer cycles, with only 1 blastocyst. Blastocysts were made from ICSI cycles and cultured by timelapse system. Patients were evaluated for pregnancy outcomes by $\beta$ hcg testing on day 14 post-embryo transfer and follow-up ultrasound until the ongoing pregnancy, at 10 weeks. Results: the $\beta$ hcg $(+)$ rate, the clinical pregnancy rate, the ongoing pregnancy rate were $62,5 \%, 55,7 \%$, $51,1 \%$ respectively. The pregnancy rate of the group without abnormality in division were higher than that in the group with abnormality at 2 stages of division, the $\beta$ hcg $(+)$ rate $(67 \%$ vs $51 \%)$, the clinical pregnancy rate $(61 \%$ vs $41 \%)$, and the ongoing rate ( $56 \%$ vs $37 \%$ ), the difference is no significant. There was no case of pregnancy after embryo transfer with vaculation in blasomere. Conclusion: embryos that did not appear abnormal division during the early stage of development will have a better pregnancy outcome than embryos with abnormalities present twice. However, studies with larger sample sizes are needed to obtain more reliable results.

\section{I. ĐĂTT VẤN ĐỀ}

Hiện nay, ngành Hỗ trợ sinh sản đã có nhiều bước tiến vượt bậc, các kỹ thuật và máy móc hiện đại ra đời giúp nâng cao kết quả của một chu kỳ thụ tinh ống nghiệm. Một trong số đó phải kể đển phương pháp nuôi cấy phôi bằng hệ thống tủ nuôi cây theo dõi liên tục (timelapse). So sánh với phương pháp nuôi cấy phôi truyền thống, khi các tủ nuôi cấy phôi không gắn camera theo dõi, việc đánh giá chất lượng hình thái và tốc độ phát triển chỉ được tiến hành ở một thời gian cố định cụ thể trong ngày bởi các chuyên viên phôi học. Việc lấy các đĩa nuôi cấy ra khỏi tủ nuôi cấy để chụp ảnh có thể ảnh hưởng đến sự phát triển của phôi do tác động trực tiếp và điều kiện nuôi cấy. Với việc áp dụng tủ nuôi cấy timelapse, các hoạt động phân chia của phôi sẽ được ghi laai liên tục, qua đó, có thể phát hiện được các bất thường xuất hiện trong 